\title{
A VISITA DA VACINA
}

\author{
NATÁLIA FAZZIONI ${ }^{1}$
}

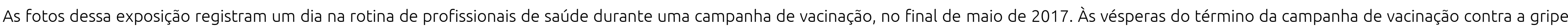

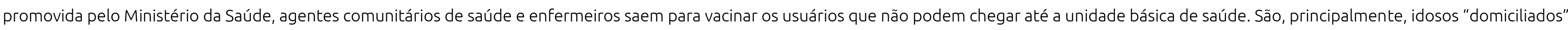

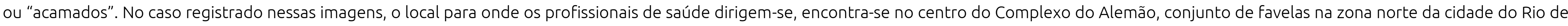
Janeiro, mais especificamente nas áreas conhecidas como Areal e Morro do Alemão.

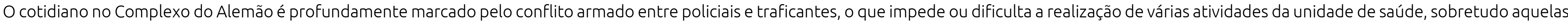

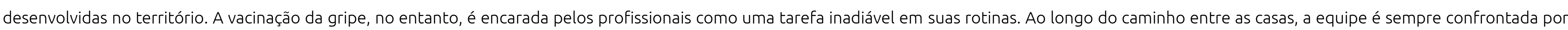

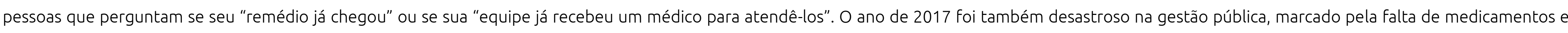
atrasos salariais.

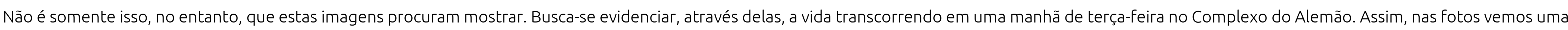

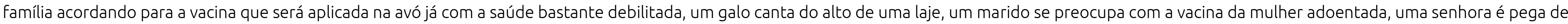

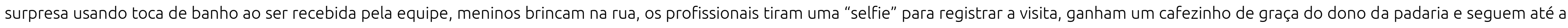
última casa registrada para vacinação, já quase na hora do almoço. 


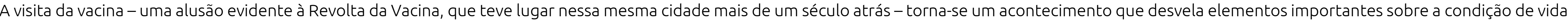

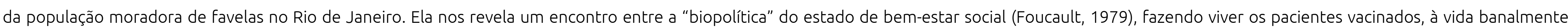

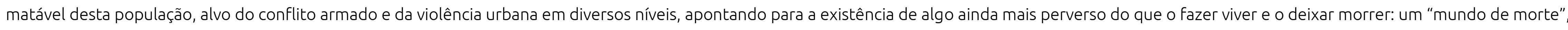

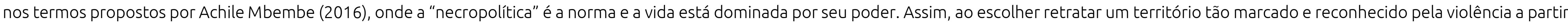

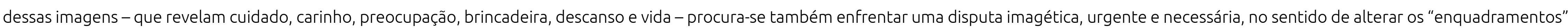
(Butler, 2015) possíveis destes espaços e das pessoas que nele vivem.

Agradeço, finalmente, aos profissionais de saúde Arlindo, Zilma e Robson que me permitiram acompanhá-los nesse dia de trabalho e autorizaram a exibição das fotografias.

REFERÊNCIAS

BUTLER, Judith. Quadros de Guerra: quando a vida é passível de luto?Rio de Janeiro: Civilização Brasileira, 2015. FOUCAULT, Michel. Microfísica do Poder. Rio de Janeiro: Edições Graal, 1979. MBEMBE, Achile. "Necropolítica”. Revista Artes \& Ensaios, n. 32, 2016. 

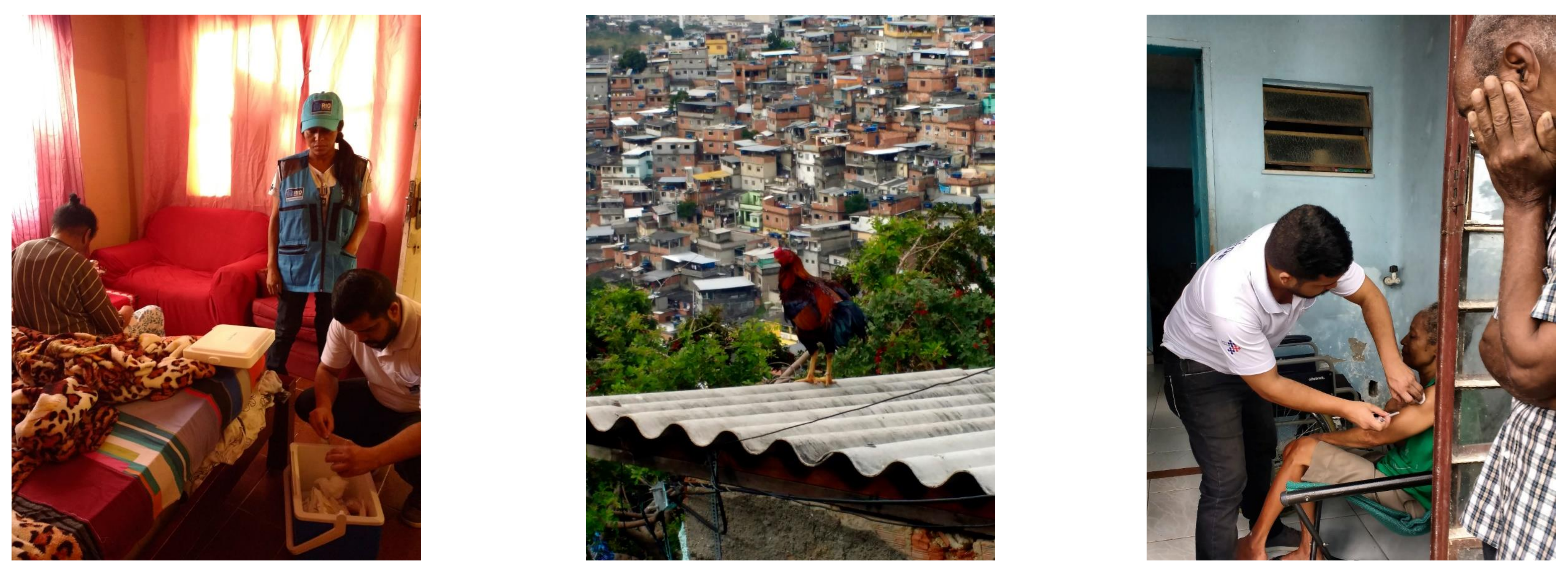

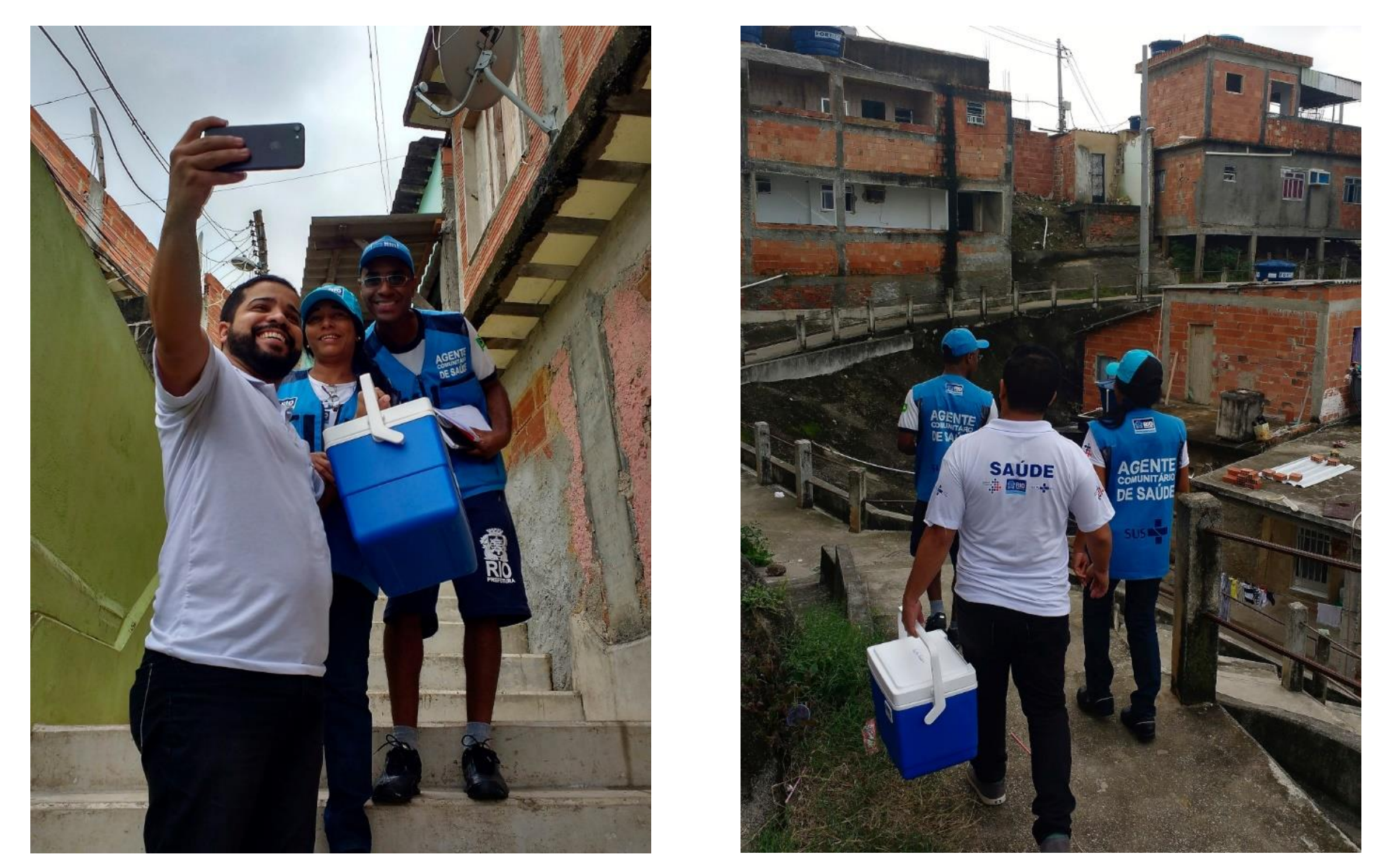

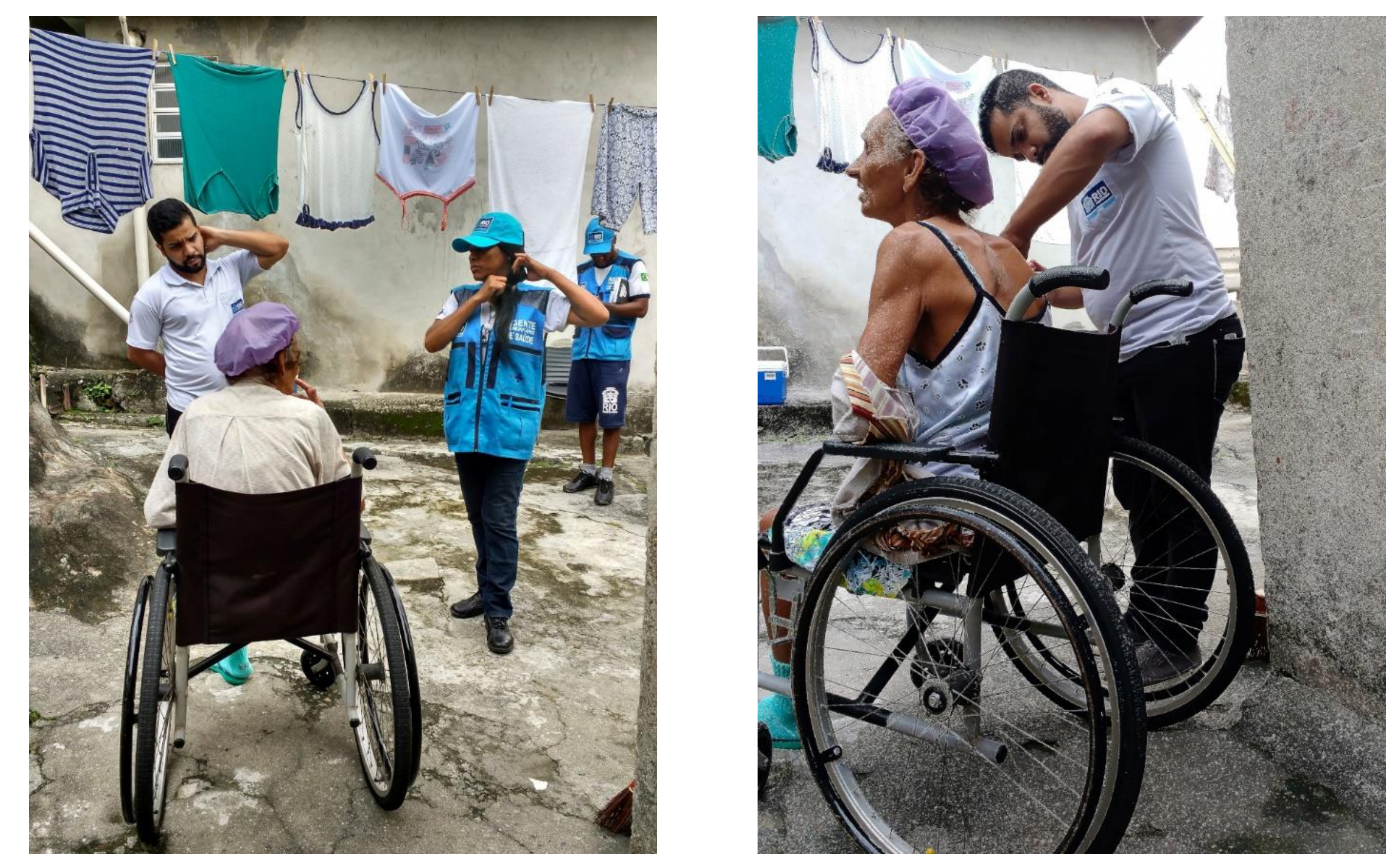

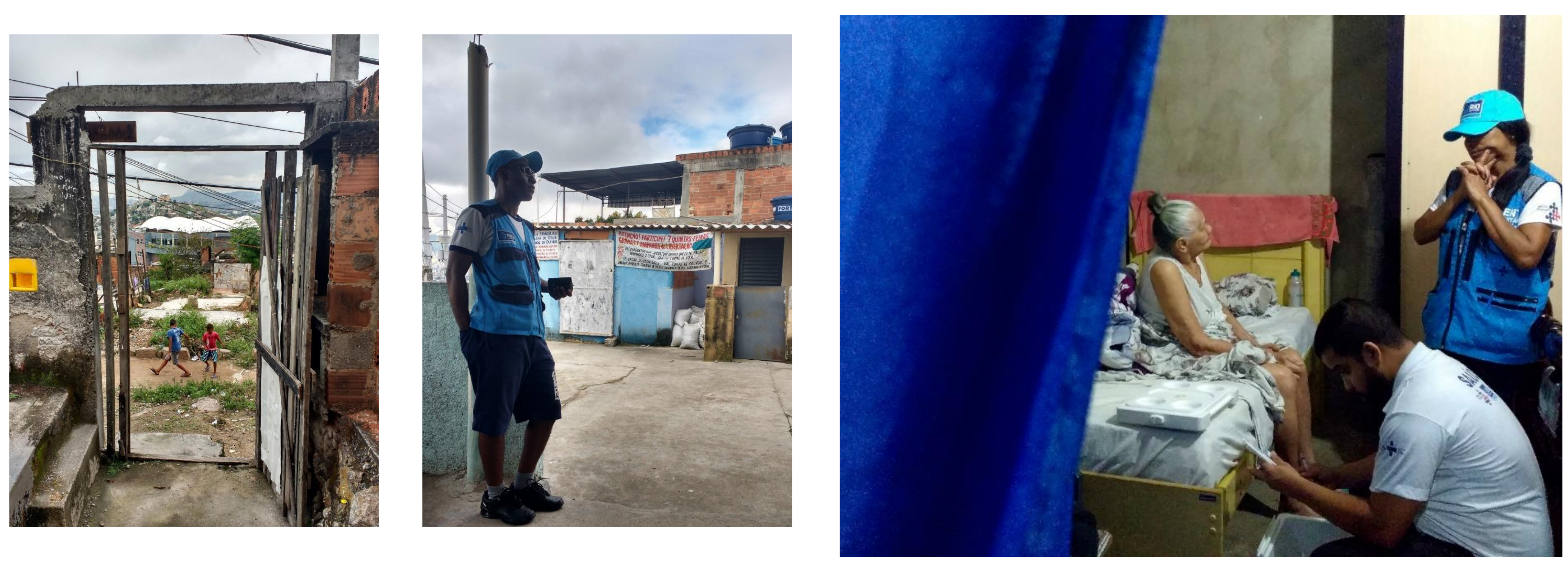
